\title{
Magnetic Nanostructures for Biomedical Applications: An Iron Nitride Crystal/Cationic Lipid Nanocomposite for Enhanced Magnetically Guided RNA Interference in Cancer Cells
}

\author{
Yoshihisa Namiki ${ }^{1}$, Satoshi Matsunuma ${ }^{2}$, Tetsutaro Inoue ${ }^{2}$, Shigeo Koido ${ }^{3}$, \\ Akihito Tsubota ${ }^{1}$, Yoji Kuse ${ }^{4}$ and Norio Tada ${ }^{1}$ \\ ${ }^{1}$ Institute of Clinical Medicine and Research, The Ikei University School of Medicine 163-1 \\ Kashiwa-shita, Kashiwa, Chiba, 277-8567 \\ ${ }^{2}$ Division of Research and Development, Hitachi Maxell \\ 1-1-88 Ushitora, Ibaraki,Osaka, 567-8567 \\ ${ }^{3}$ Divisoin of Gastroenterology, The thei University School of Medicine \\ 163-1 Kashiwa-shita, Kashiwa, Chiba, 277-8567 \\ ${ }^{4}$ Giken Parts CO. LTD. 290 Sugimoto-cho, Tenri, Nara, 632-0078 \\ ctopan
}

\section{Introduction}

Cancer is a major cause of death throughout the world, especially in the industrially developed nations. Minimally invasive and effective treatments are thus urgently required. Small interfering RNA (siRNA) is a possible candidate because it selectively decomposes and silences the target genes (Fire et al., 1998) associated with disease progression. However, the obstacle to the development of siRNA as a therapeutic agent results from the absence of an effective system for delivering siRNA to the target region ( $\mathrm{Li}$ et al., 2006; Toub et al., 2006).

In this context, we previously devised functional nanoparticles composed of iron oxide crystals as the siRNA-delivery system to magnetically augment the accumulation of siRNA at target regions (Namiki et al., 2009). Among the magnetic materials available for biomedical applications, including gene delivery, iron oxide forms, such as magnetite $\left(\mathrm{Fe}_{3} \mathrm{O}_{4}\right)$ and maghemite $\left(\gamma-\mathrm{Fe}_{2} \mathrm{O}_{3}\right)$, have been widely investigated (Xie et al., 2009; Lin et al., 2008; Laurent et al., 2008; Gupta et al., 2005) because of their comparatively low cytotoxicity and dependable degree of magnetism.

In the field of information technology, meanwhile, various kinds of magnetic storage devices, such as floppy disks, hard disks and magneto-optical disks have been developed. Among the ferromagnetic materials used in ultra-high density storage devices, iron nitride has several advantages, as follows (Sugita et al., 1994; Takahashi et al., 1999; Hattori et al., 2001). (1) Iron nitride displays a greater degree of magnetization compared with iron oxide, 
even when the nanocrystal-size is small. (2) Iron nitride is an iron-based material, and iron is cheap and abundant. (3) Iron nitride is a much cheaper ferromagnetic material than other ferromagnetic materials, such as FePt (Sun et al., 2000). (4) Iron nitride is made from nontoxic and decomposable chemical elements such as iron and nitride. The spherical iron nitride nanocrystal is therefore an attractive material, not only as an ultra-high density data storage device, but also as a gene therapy vector in biomedical technology fields.

The absorption force of magnetic nanoparticles to a magnet can be enhanced by the optimization of the magnetic materials. Furthermore, for biomedical applications, iron nitride is expected to be a good magnetic material candidate if it is able to display a similar low degree of cytotoxicity as iron oxide. However, iron nitride nanoparticles for biomedical applications have not been previously reported. We have devised an innovative $\mathrm{Fe}_{16} \mathrm{~N}_{2} /$ cationic lipid nanocomposite and tested it in the magnetically guided silencing of target genes in cancer cells. Through an interdisciplinary fusion of the advances in various scientific fields, we were able to develop a novel gene delivery tool. This tool is comprised of magnetic nanoparticles composed of an iron nitride nanocrystal-core and a cationic lipidshell with high affinity genes.

In this chapter, we describe the enhanced magnetism and gene silencing effect of a magnetic nanocomposite made from iron nitride instead of the conventionally used iron oxide, and we report the potential of the iron nitride/ cationic lipid nanocomposite as magnetically guided gene therapeutic vector which delivers siRNA into cells. Initially, we describe the preparation and purification procedures used for this nanocomposite. We prepared a magnetic fluid in which oleic acid-coated iron nitride nanocrystals were dispersed in chloroform. Through a further development of our previously devised procedure (Namiki et al., 2009), the oleic acid-coated iron nitride was assembled with the cationic lipid via hydrophobic interaction. Subsequently, we report the morphological and physiological properties of this composite, termed LipoFeN. In addition, siRNA designed to knockdown target genes and cationic lipid-coated iron nitride nanocrystals were mixed to form the complexes through electrostatic force. Finally, we show the degree of magnetic attraction, gene silencing effect and cytotoxic effect of this siRNA-loaded nanocomposite.

\section{Preparation and morphology of the iron nitride/metallic oxide core shell nanostructure}

Initially, magnetite nanocrystals with an approximate $20 \mathrm{~nm}$ diameter were synthesized as follow s. $\mathrm{FeCl}_{3}$ (0.04 mol; Wako, Tokyo, Japan) and $\mathrm{FeCl}_{2}$ (0.02 mol; Wako) were dissolved in $25 \mathrm{ml}$ of distilled water. When $25 \mathrm{ml}$ of ammonium hydroxide (25\%) were vigorously mixed with this solution, magnetite slurry was precipitated. Subsequently, on the surface of the dried magnetite nanocrystals, yttrium and aluminum were deposited in the solutiondispersed magnetite nanocrystals. These dried particles were deoxidized with hydrogen gas and then continuously treated with $\mathrm{NH}_{3}$ gas. Finally, the iron nitride/ metallic oxide core shell nanostructure was obtained (Sasaki et al., 2005). The shell layer, which is composed of yttrium-oxide and aluminum oxide, has the roles of preventing iron nitride oxidization and decomposition, and thus of maintaining the magnetism of the iron nitride. The nanostructure was examined using transmission electron microscopy (TEM), which revealed that this nanocomposite has an average diameter of $26 \mathrm{~nm}$ and approximate $3.5 \mathrm{~nm}$ shell thickness (Fig. 1). 

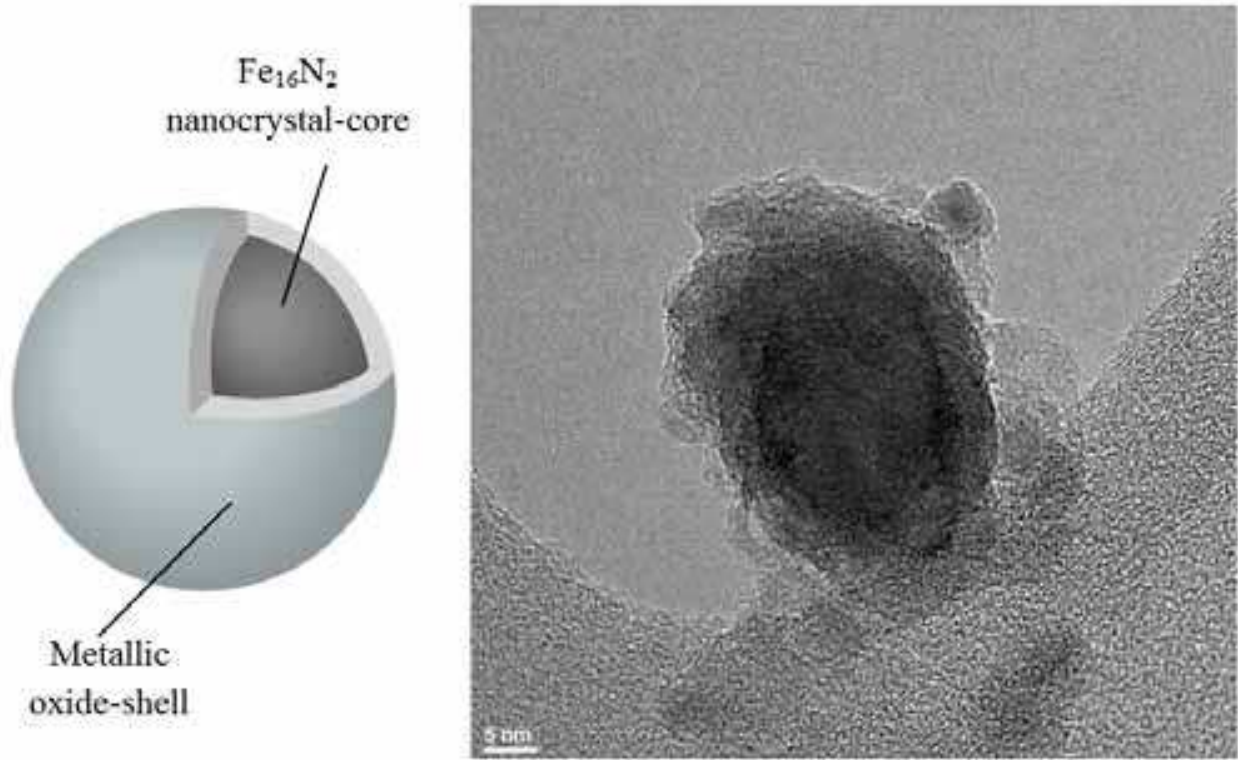

Fig. 1. Schematic representation and transmission electron micrograph of the $\mathrm{Fe}_{16} \mathrm{~N}_{2} /$ metal oxide core shell nanocomposite.

\section{Physiological properties of the iron nitride/metallic oxide core shell nanostructure}

The crystal structure of the particles was examined with an X-ray diffractometer (XRD). The surface condition was investigated using X-ray photoelectron spectroscopy (XPS). Magnetic measurements were carried out using a vibration sample magnetometer (VSM) by applying the maximum field of $1270 \mathrm{kA} / \mathrm{m}(16 \mathrm{kOe})$.

Data was acquired using a coupled Theta: 2-Theta scan on a Rigaku Ultima-III diffractomer equipped with a copper x-ray tube, parafocusing optics, computer-controlled variable slits, and a diffracted beam monochromator. Figure 2 shows the best matches after comparing the background-subtracted raw data with that of the ICDD/ ICSD diffraction database. As expected, the primary phase is $\mathrm{Fe}_{16} \mathrm{~N}_{2}$. There is also a small amount of maghemite. Note that the primary maghemite peak, near 36 degrees on 2-Theta, is somewhat shifted relative to the reference pattern. This indicates that the Fe:O ratio may be somewhat different than 2:3. Note also that no metallic iron was detected. This phase is strongly overlapped with $\mathrm{Fe}_{16} \mathrm{~N}_{2}$, so trace amounts of $\mathrm{Fe}$ in $\mathrm{Fe}_{16} \mathrm{~N}_{2}$ might not be detected.

XPS data is quantified using relative sensitivity factors and a model that assumes a homogeneous layer. The analysis volume is the product of the analysis area (spot size or aperture size) and the depth of information. Photoelectrons are generated within the X-ray penetration depth (typically some number of microns), but only the photoelectrons within the top three photoelectron escape depths are detected. Escape depths are on the order of 15-35 ^, which leads to an analysis depth of $\sim 50-100 \AA$. Typically, 95\% of the signal originates from within this depth. 


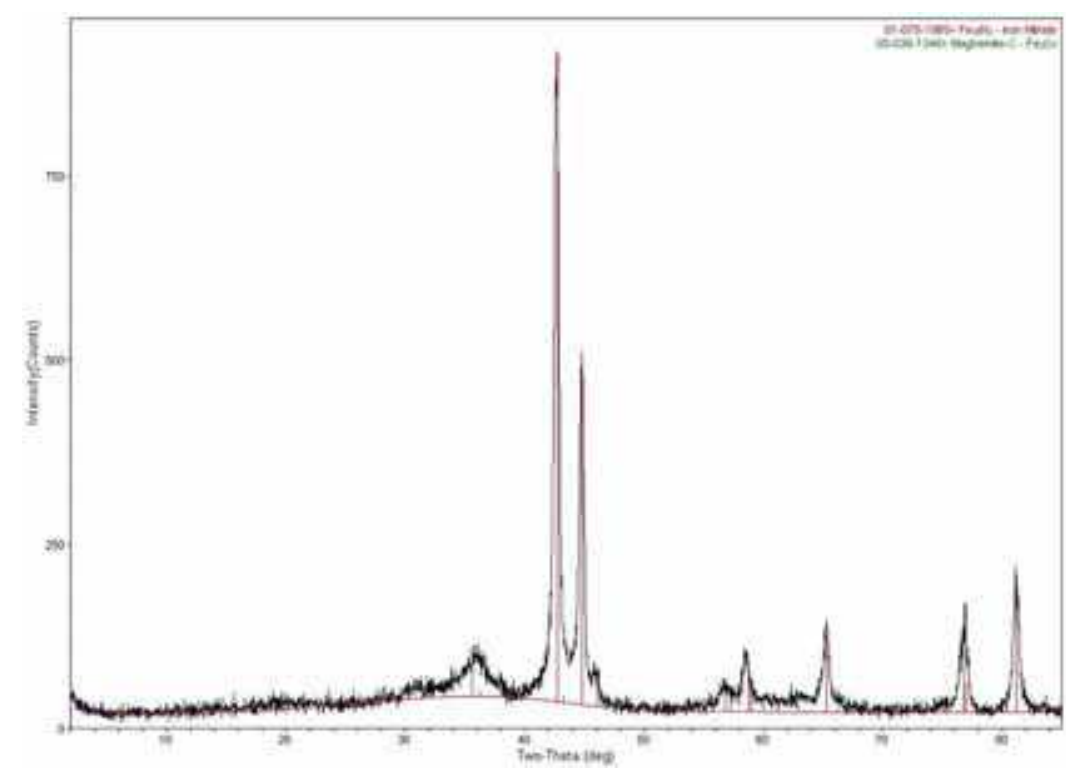

Fig. 2. X-ray diffraction peaks originating in the $\mathrm{Fe}_{16} \mathrm{~N}_{2}$ / metal oxide core shell nanocomposite were clearly observed.

\begin{tabular}{|l|l|}
\hline Instrument & PHI Quantum 2000 \\
\hline X-ray source & Monochromated Alka 1486.6eV \\
\hline Acceptance Angle & $\pm 23^{\circ}$ \\
\hline Take-off angle & $45^{\circ}$ \\
\hline Analysis area & $1400 \mathrm{~mm} \times 300 \mathrm{~mm}$ \\
\hline Charge Correction & C1s $284.8 \mathrm{eV}$ \\
\hline
\end{tabular}

Table 1. Analytical parameters of XPS.

Table 2 provides the atomic concentrations of the elements detected. The values given are normalized to $100 \%$ using the elements detected. Detection limits are approximately 0.05 to 1.0 atomic \%. The major factors affecting the detection limit are the element itself, interference and background. Chemical state assignments for a given element were made by consulting the reference data from the literature. Chemical state assignments must be considered as tentative in cases where the available reference data is limited or in cases where similar binding energies are observed for a number of different chemical states. Nonlinear least squares (NLLS) curve fitting has been applied to selected high resolution spectra to assist in possible chemical state assignment. The results of the NLLS fits are shown on the individual spectra. It should be noted that the curve fit routines are mathematical devices, and for a given peak a number of mathematically valid results may exist.

1. The particle surfaces are predominantly composed of aluminum, iron, oxygen and carbon, with low levels of yttrium and trace levels of fluoride, magnesium and chlorine (Table 2).

2. Aluminum is found within the cap of the binding energies consistent with $\mathrm{Al}_{2} \mathrm{O}_{3}$ (Fig. $3 b)$. While various reports on YxAlyOx have comparable aluminum binding energies, the yttrium data below suggests that such a species is not present in these samples. 
3. Yttrium is found at a binding energy (157.8eV, Fig. 3c) most consistent with that of $\mathrm{Y}(\mathrm{OH})_{3}(157.7 \mathrm{eV})$. Its binding energy is higher than that for the $\mathrm{Y}_{2} \mathrm{O}_{3}$ reference $(\sim 156.3 \mathrm{eV})$. The yttrium binding energy for an $\mathrm{Y}_{3} \mathrm{Al}_{5} \mathrm{O}_{12}$ reference run was found to be $157.1 \mathrm{eV}$. Thus, the yttrium in this sample is most likely present in the form $\mathrm{Y}(\mathrm{OH})_{3}$.

4. Iron is found predominantly as iron oxide, likely $\mathrm{Fe}_{2} \mathrm{O}_{3}$, based in part on the XRD data. Additionally, low levels of Fe nitride are present (Fig. 3b, Table 2). It is noted that XRD found the opposite (high levels of iron nitride with trace levels of $\mathrm{Fe}_{2} \mathrm{O}_{3}$ ). This discrepancy is due to sampling depth differences (i.e. XRD samples the entire particle, whereas XPS samples only the top $60-80 \AA$ ).

5. Trace levels of fluorine and chlorine are found as inorganic fluorides and chlorides, respectively. These may be associated with iron, magnesium, yttrium or aluminum. The levels are insufficient to allow confirmation using the respective spectra.

6. Carbon is found predominantly as a hydrocarbon (C-C, C-H), with lower levels of oxigen-containing species, potentially including $\mathrm{CO}_{3}$ (data not shown). The low carbon levels observed coupled with its chemistry indicates that much, possibly all, of the carbon is present as adventitious carbon, which had adsorbed onto sample surfaces from the atmosphere.

7. Magnesium does not exhibit any significant shift in its binding energies in different chemical states.

8. Oxygen is present as a complex mixture of metal oxides/ hydroxides and organic oxygen.

9. Note that the presence of low levels of nitrogen cannot be confirmed in this system due to interference from a secondary yttrium signal (data not shown). However, based on the low levels of iron nitride present (from the iron data) and the low nitrogen/ iron ratio (based on XRD having determined the iron nitride to be $\mathrm{Fe}_{16} \mathrm{~N}_{2}$ ), nitrogen would only be present within the XPS information depth at concentrations of $0.07 \%$, i.e. below the XPS detection limit for this element.

The particle surfaces are composed predominantly of $\mathrm{Al}_{2} \mathrm{O}_{3}$, with lower levels of $\mathrm{Y}(\mathrm{OH})_{3}$ on $\mathrm{Fe}_{2} \mathrm{O}_{3}$. Only low levels of iron nitride $\left(\mathrm{Fe}_{16} \mathrm{~N}_{2}\right.$ based on the XRD data) are observed, indicating that XPS does not reach deep into the particle core (Table 3). Additionally, trace levels of inorganic chlorides, fluorides and magnesium are present.

\begin{tabular}{|ccccccccc|}
\hline $\mathbf{C}$ & $\mathbf{N}$ & $\mathbf{O}$ & $\mathbf{F}$ & $\mathbf{M g}$ & $\mathbf{A l}$ & $\mathbf{C l}$ & $\mathbf{F e}$ & $\mathbf{Y}$ \\
\hline 9.9 & ${ }^{\mathrm{b}} \boldsymbol{?}$ & 62.1 & 0.7 & 0.6 & 16.0 & 0.2 & 8.3 & 2.3 \\
\hline
\end{tabular}

Table 2. Atomic concentrations (in \%)a

a Normalized to $100 \%$ of the elements detected. XPS does not detect $\mathrm{H}$ or $\mathrm{He}$.

b The presence of $\mathrm{N}$ could not be confirmed due to the interference from a secondary $\mathrm{Y}$ signal.

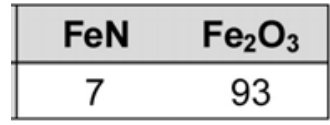

Table 3. Iron chemical state (in \% of total $\mathrm{Fe}^{\mathrm{a}}$ )

a The values in this table are percentages of the total atomic concentrations of the corresponding element shown in Table 2. 


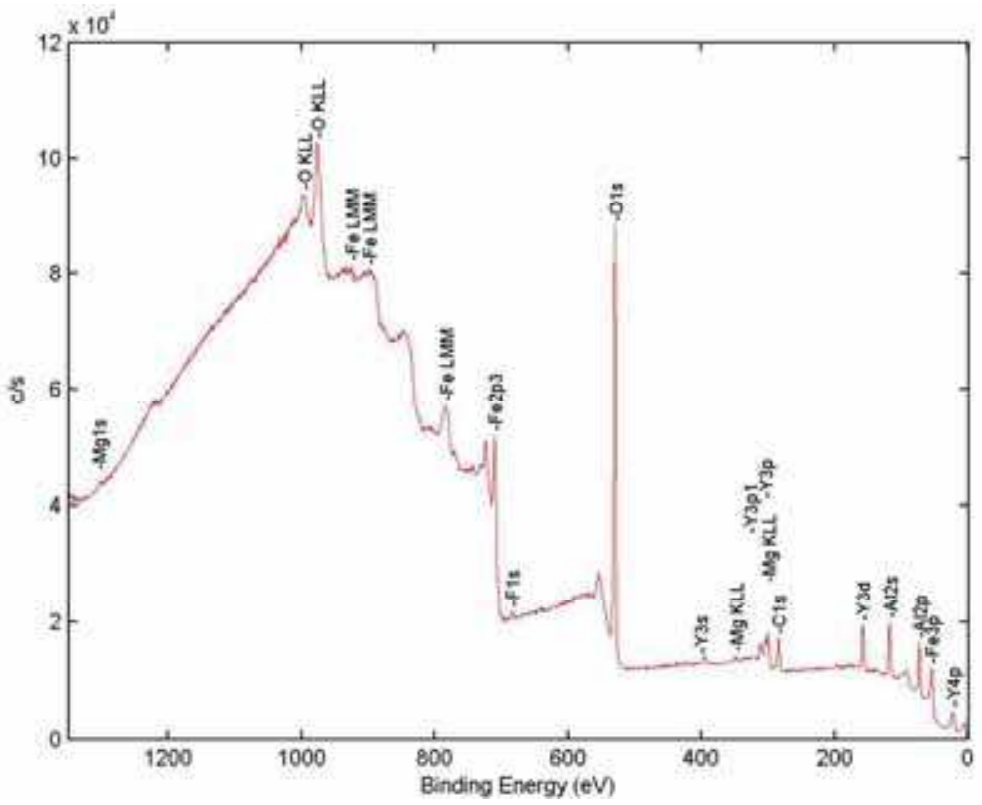

(a)

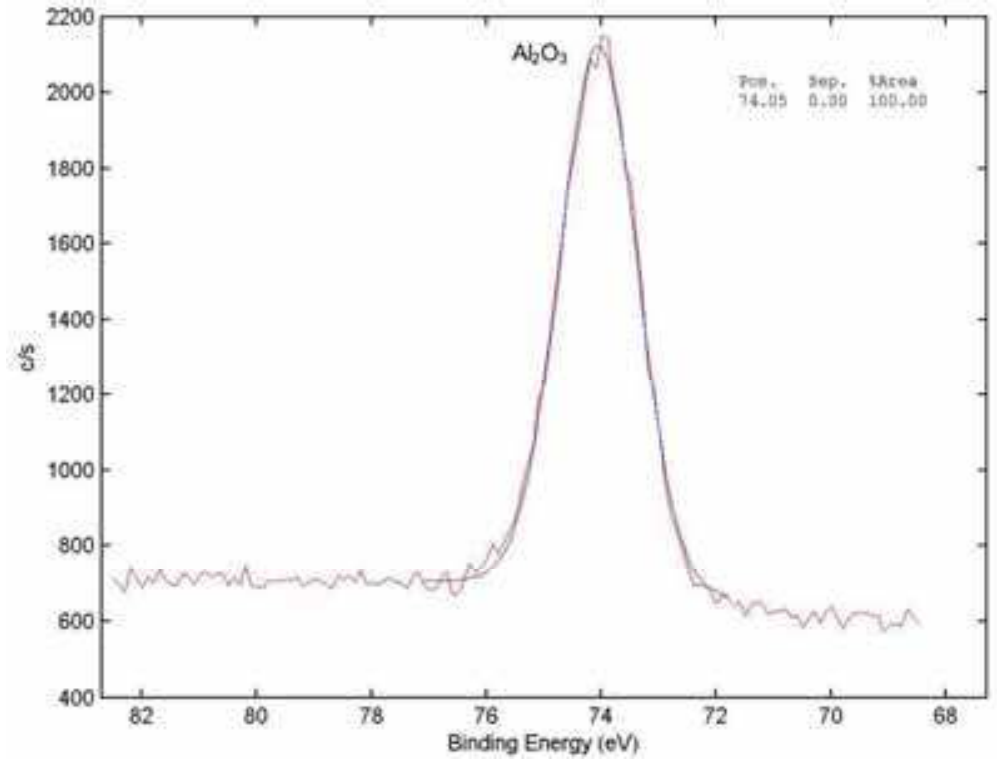

(b) 
Magnetic Nanostructures for Biomedical Applications: An Iron Nitride Crystal/Cationic

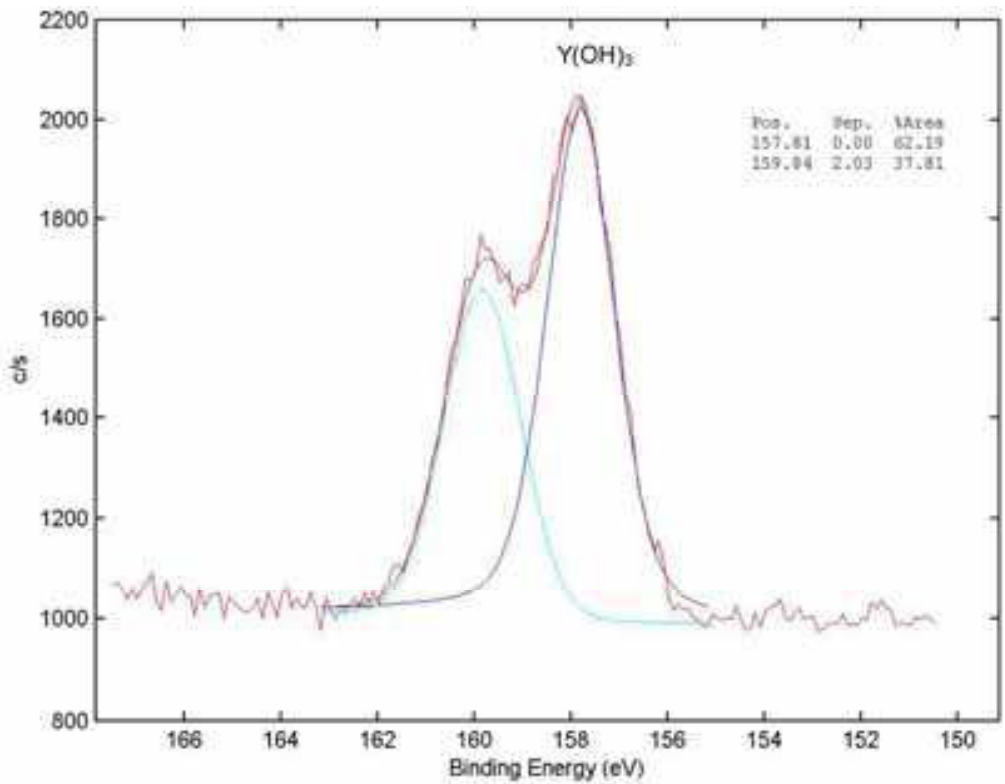

(c)

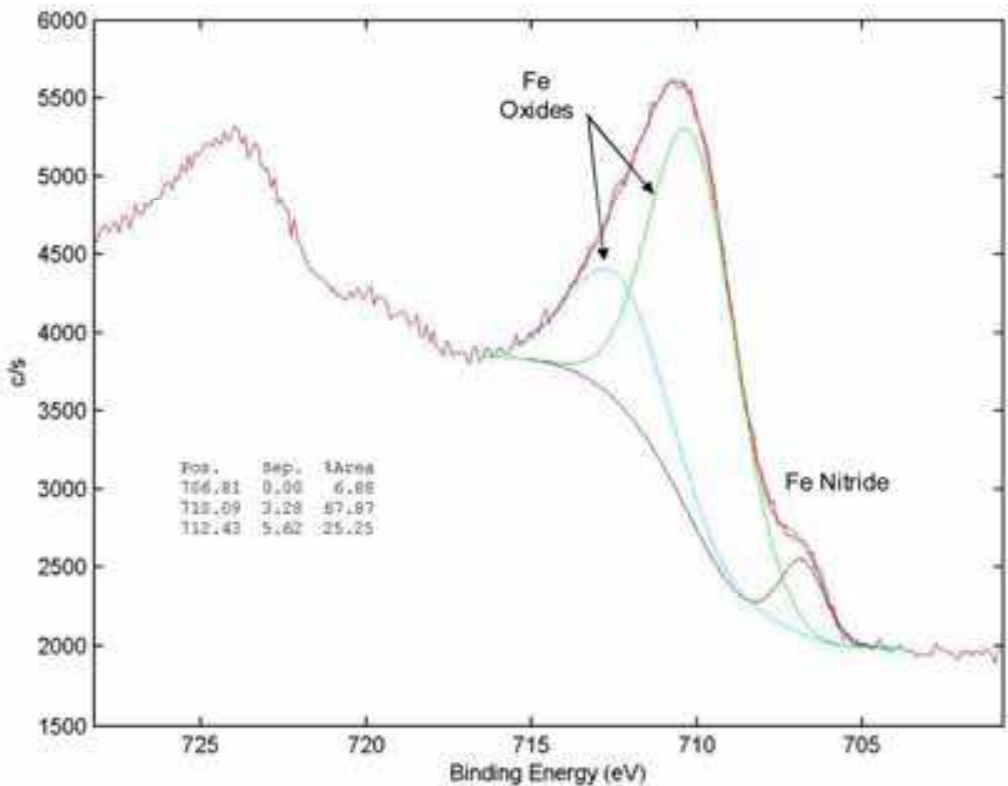

(d)

Fig. 3. The X-ray photoelectron spectroscopy profiles indicated that the metalic oxide shell was composed of aluminum ( $\mathrm{Al})-$, yttrium $(\mathrm{Y})$ - and iron $(\mathrm{Fe})$ - oxides. 
In terms of magnetism, $\mathrm{Fe}_{16} \mathrm{~N}_{2} /$ metalic oxide nanocomposite displayed saturation magnetization $\left(103.1 \mathrm{emu} / \mathrm{g}\right.$ ) and coercive force (3055 Oe), while $\mathrm{Fe}_{3} \mathrm{O}_{4}$ displayed 50.8 emg/ g and 0 Oe (Fig. 4).

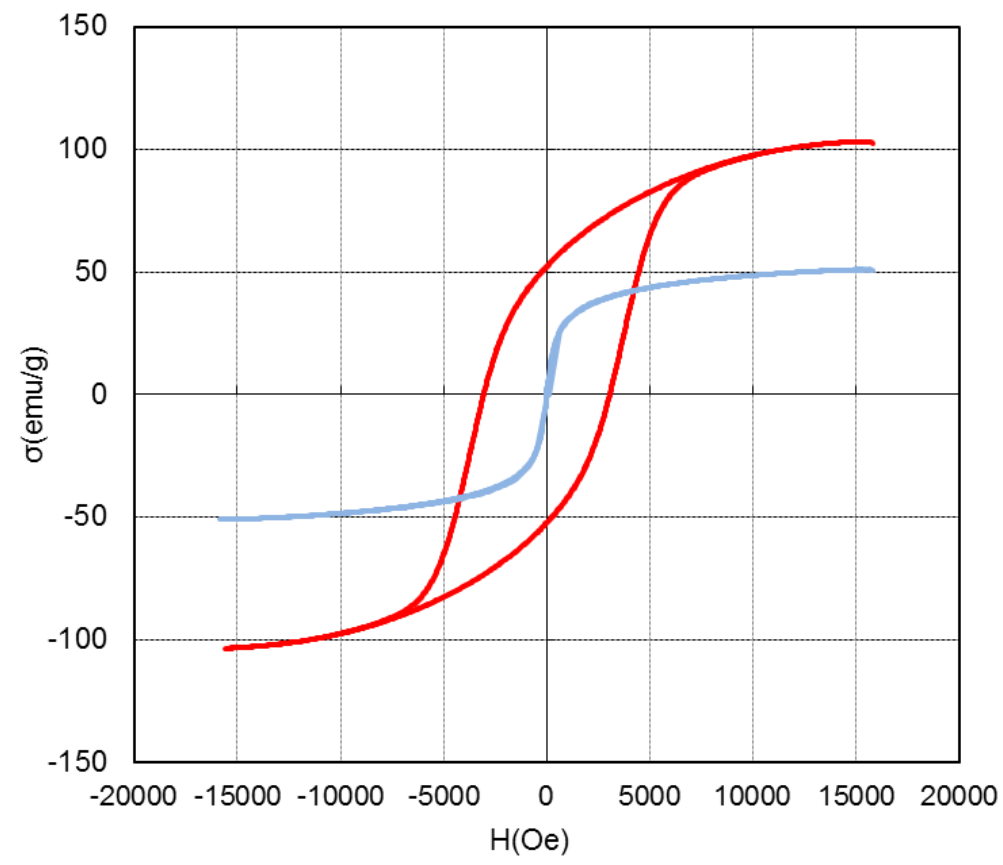

Fig. 4. The magnetization curve of the $\mathrm{Fe}_{16} \mathrm{~N}_{2}$ metalic oxide nanocomposite and $\mathrm{Fe}_{3} \mathrm{O}_{4}$. $\mathrm{Fe}_{16} \mathrm{~N}_{2} /$ metallic oxide, red; $\mathrm{Fe}_{3} \mathrm{O}_{4}$, blue.

\section{Preparation of iron nitride/metallic oxide/oleic acid-based magnetic fluid}

The air-dried iron nitride/ metallic oxide core shell nanostructure was well dispersed in ammonium hydroxide (25\%). This mixture was then heated to $95^{\circ} \mathrm{C}$ and $55 \mathrm{ml}$ of $10 \%$ oleic acid (Wako)/ dodecan (Wako) were added. In this process, the FeN-nanocomposites were coated with hydrophilic ammonium oleate, and the ammonium oleate began to decompose at $78{ }^{\circ} \mathrm{C}$, with the evaporation of ammonia gas thus changing the FeN-nanocomposites coated with hydrophobic oleic acid upon continuous heating. As a result, a distinct phase separation between the upper organic portion, in which the oleic acid-coated FeNnanocomposites were stably dispersed, and the lower aqueous portion appeared. Most of the aqueous phase was removed using a pipette and the heating of the residue was continued until the remaining water had been completely evaporated. The oleic acid-coated FeN-nanocomposites were flocculated by the addition of $100 \mathrm{ml}$ of acetone, and a permanent magnet was used to collect this magnetic flocculate while the supernatant liquid was poured off. Moreover, this flocculate was then washed with $80 \mathrm{ml}$ of acetone to eliminate excess oleic acid and centrifuged at $800 \mathrm{G}$. Acetone was completely removed from the resulting precipitation under reduced pressure $(10 \mathrm{mmHg})$ at room temperature. 
Twenty micrograms of these dried oleic acid-coated FeN-nanocomposites were dispersed in $5 \mathrm{ml}$ of chloroform, so a chloroform-based magnetic fluid was finally obtained (Fig. 5, 6).

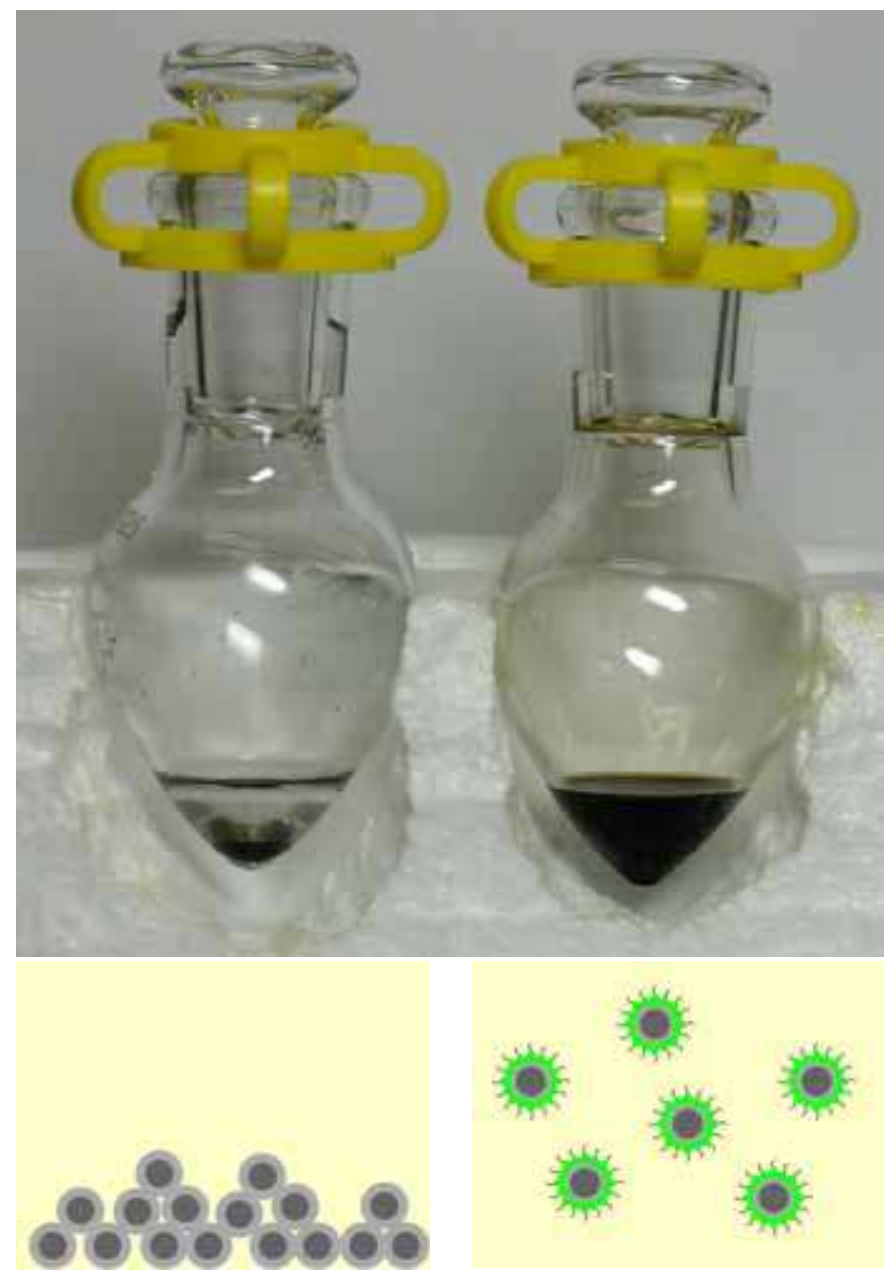

Fig. 5. Dispersion of the oleic acid-coated $\mathrm{Fe}_{16} \mathrm{~N}_{2} /$ metalic oxide nanocomposite in chloroform. The magnetic fluid (right) was composed of the oleic acid (green)-coated iron nitride/ metallic oxide nanocomposite (dark gray light gray) dispersed in chloroform (yellow).

\section{Preparation of the iron nitride/metallic oxide/oleic acid/cationic lipid nanocomposite}

One microgram of a lipid mixture (DC-6-14 (Sogo Pharmacochemical, Tokyo, Japan): DOPE $($ Wako $)=1: 0.4$; molar ratio) was dissolved in $0.5 \mathrm{ml}$ of chloroform. The lipid mixture, along with the chloroform-based magnetic fluid containing $0.2 \mathrm{mg}$ of oleic acid-coated $\mathrm{Fe}_{16} \mathrm{~N}_{2} /$ metalic oxide nanocomposite, was introduced into a pear-shaped flask. Chloroform 


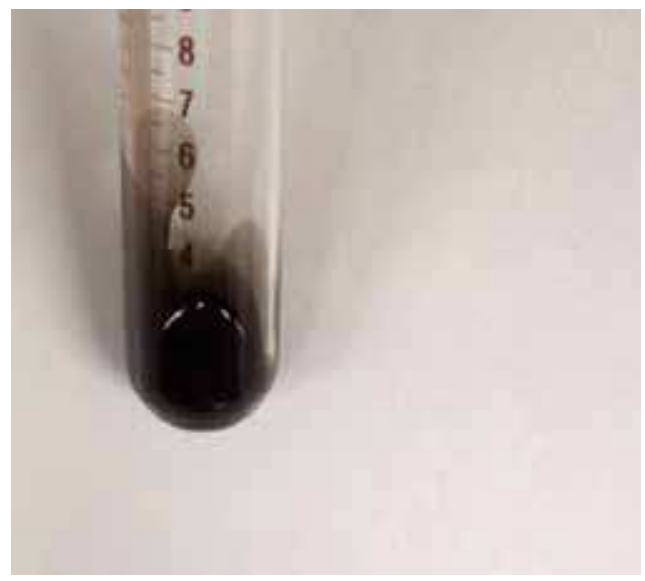

(1)

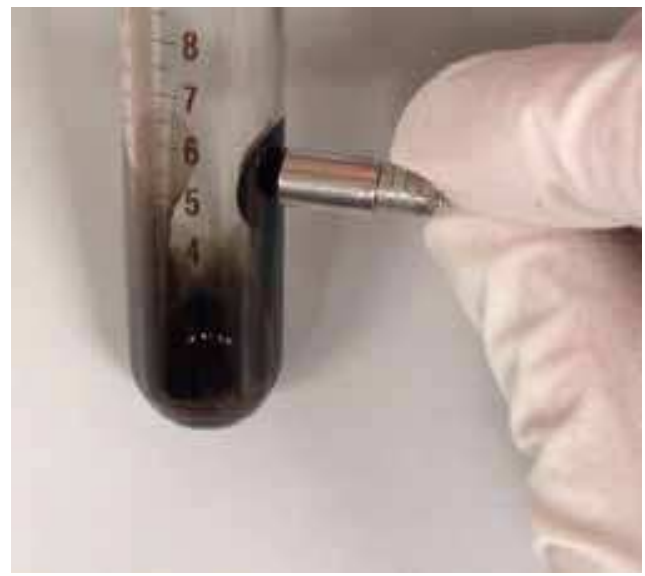

(3)

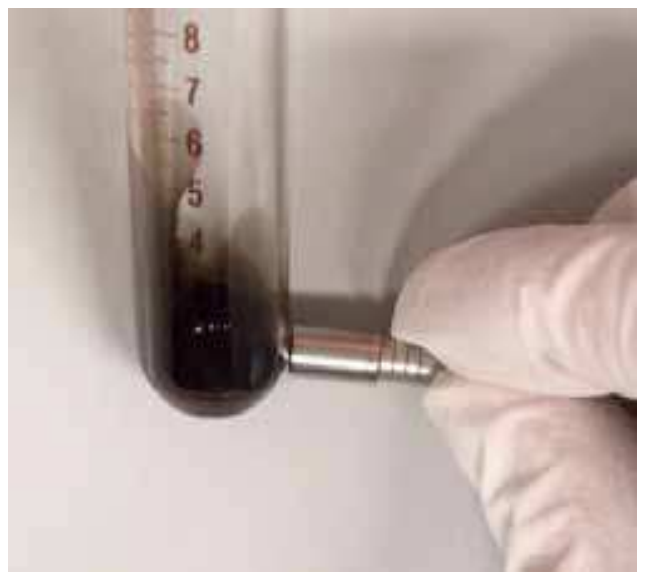

(2)

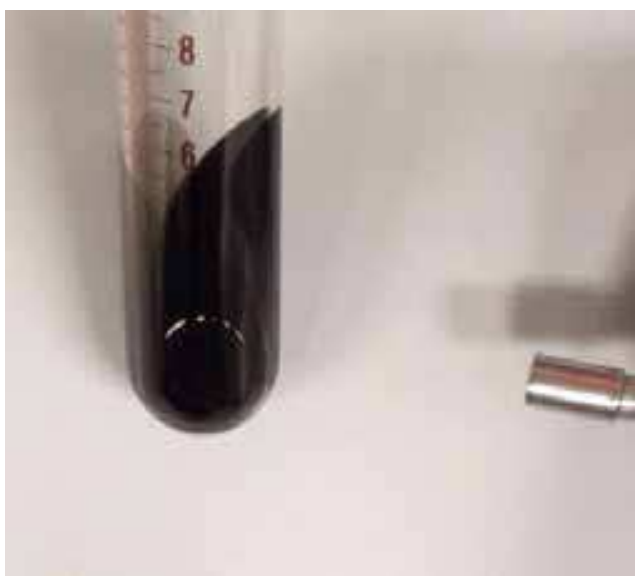

(4)

Fig. 6. Magnetic attraction of the chloroform-based magnetic fluid composed of the oleic acid-coated $\mathrm{Fe}_{16} \mathrm{~N}_{2} /$ metalic oxide nanocomposite.

was added to this flask until the total volume reached $1 \mathrm{ml}$ and mixed well. After the addition of $1 \mathrm{ml}$ of distilled water, the mixture was agitated on a vortex mixer for $1 \mathrm{~min}$ and sonicated by a cup-horn type sonicator (Sonifier 250D, Branson, CT) with a maximum output for $2 \mathrm{~min}$ at $37^{\circ} \mathrm{C}$. The flask containing a gray homogeneous suspension was attached to a rotary evaporator and rotated at $2.5 \mathrm{G}$. The contents were evaporated at $50 \mathrm{mmHg}$ under strong sonication at $37^{\circ} \mathrm{C}$. In this process, chloroform was evaporated off to yield a gel and the gel immediately collapsed to give a clear gray-colored suspension. The remaining chloroform was removed from this suspension at $10 \mathrm{mmHg}$ for $10 \mathrm{~min}$ (room temperature). This suspension was sonicated with a maximum output for $30 \mathrm{~min}$ at $37^{\circ} \mathrm{C}$, and finally, iron nitride/metallic oxide/ oleic acid/cationic lipid nanocomposite were obtained through hydrophobic interactions (Fig. 7). 


\section{Purification of the iron nitride/metallic oxide/oleic acid/cationic lipid nanocomposite from free cationic liposome.}

The magnetally attractive stainless steel (SUS 430) granule (size $0.4 \mathrm{~mm}$ ) was pressed and sintered, until finally the sintered magnetic metal filter was obtained (diameter $\mathrm{x}$ height: 9.0 $\mathrm{x} 10 \mathrm{~mm}$ ). This filter was inserted in the cylinder. Both poles of twin neodymium magnets, which were placed horizontally and oppositely arranged, were magnetically attracted on the column at the region of the stainless filter (Fig. 8). Under a magnetic field, magnetic nanoparticles were captured by the stainless steel filter of the syringe column, and magnetic crystal-free lipid vesicles lacking magnetic nanocrystals were eliminated. In the absence of a magnetic field, magnetitc nanoparticles were eluted from the filter (Fig. 9).

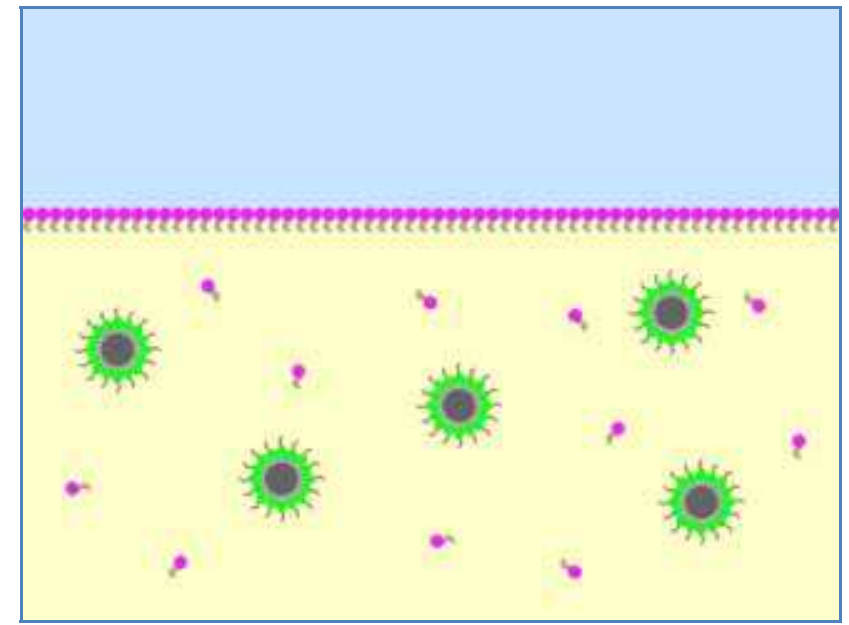

(1)

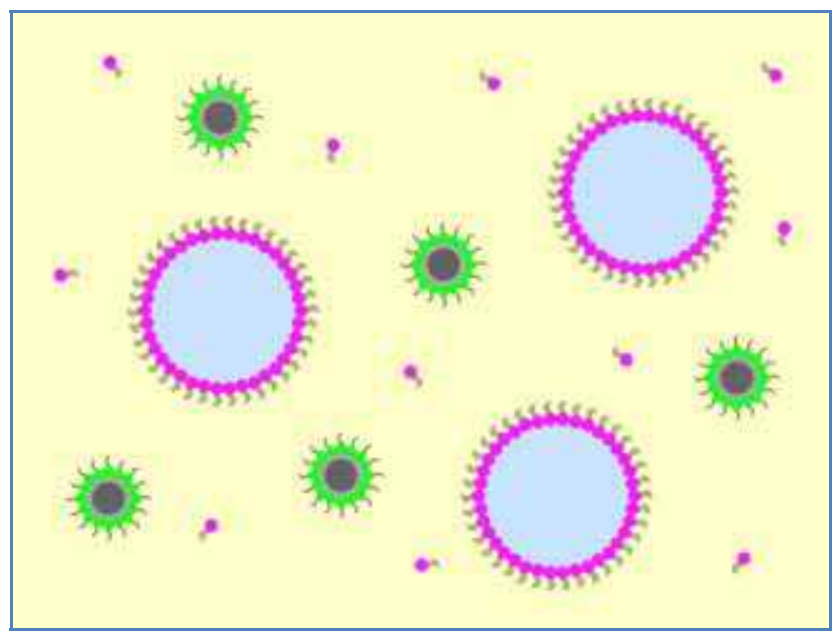

(2) 


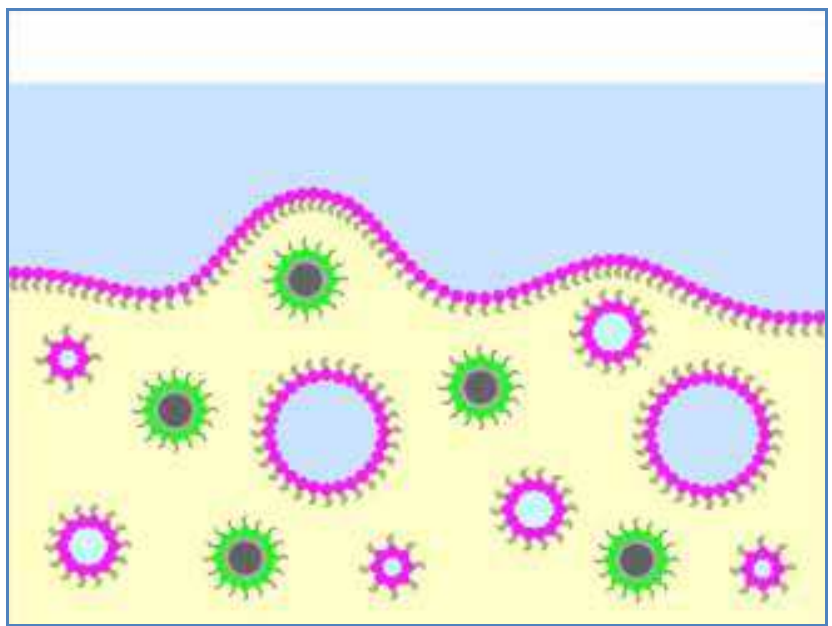

(3)

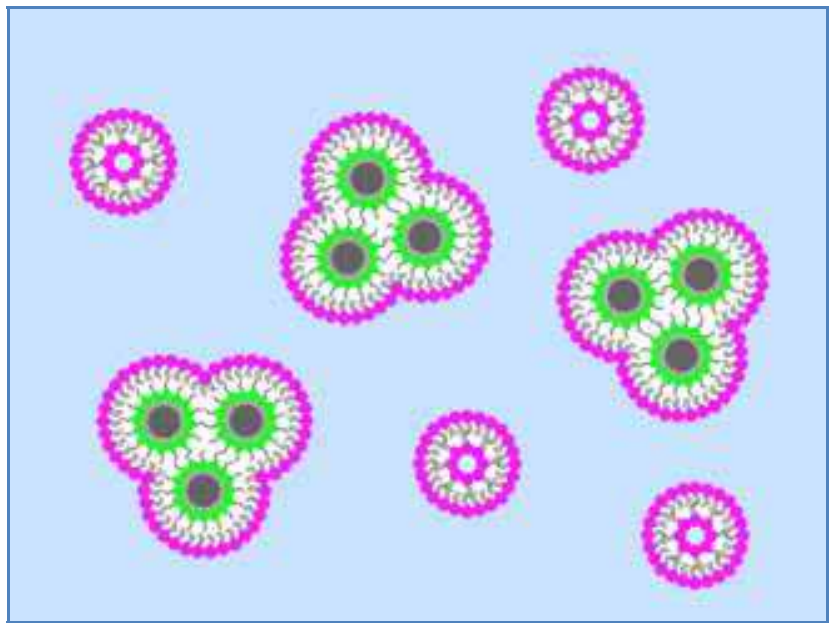

(4)

Fig. 7. Schematic representation of the preparation of the cationic lipid-coated ferromagnetic nanocomposite.

1) The magnetic fluid was composed of the oleic acid (green)-coated iron nitride/ metallic oxide nanocomposite (dark gray light gray) dispersed in chloroform (yellow). The hydrophobic chloroform-based magnetic fluid and phospholipids (pink) dissolved in chloroform were mixed. When this mixture and distilled water (blue) were poured in a pearshaped flask, an upper layer of aqueous phase and a lower layer of organic phase containing oleic acid-coated magnetic nanocrystals appeared.

2) After vigorous agitation and sonication, micro droplets were stabilized by a phospholipid layer, and "inverted micelles" formed.

3) Removal of chloroform by strong vacuuming leads to a transformation of these inverted 
micelles into a viscous gel state.

4) After the induction of gel-collapse through the continuous vacuum, the hydrophobic groups of amphiphilic phospholipids and oleic acid joined together to form the hydrophilic, cationic lipid-coated ferromagnetic nanocomposite.
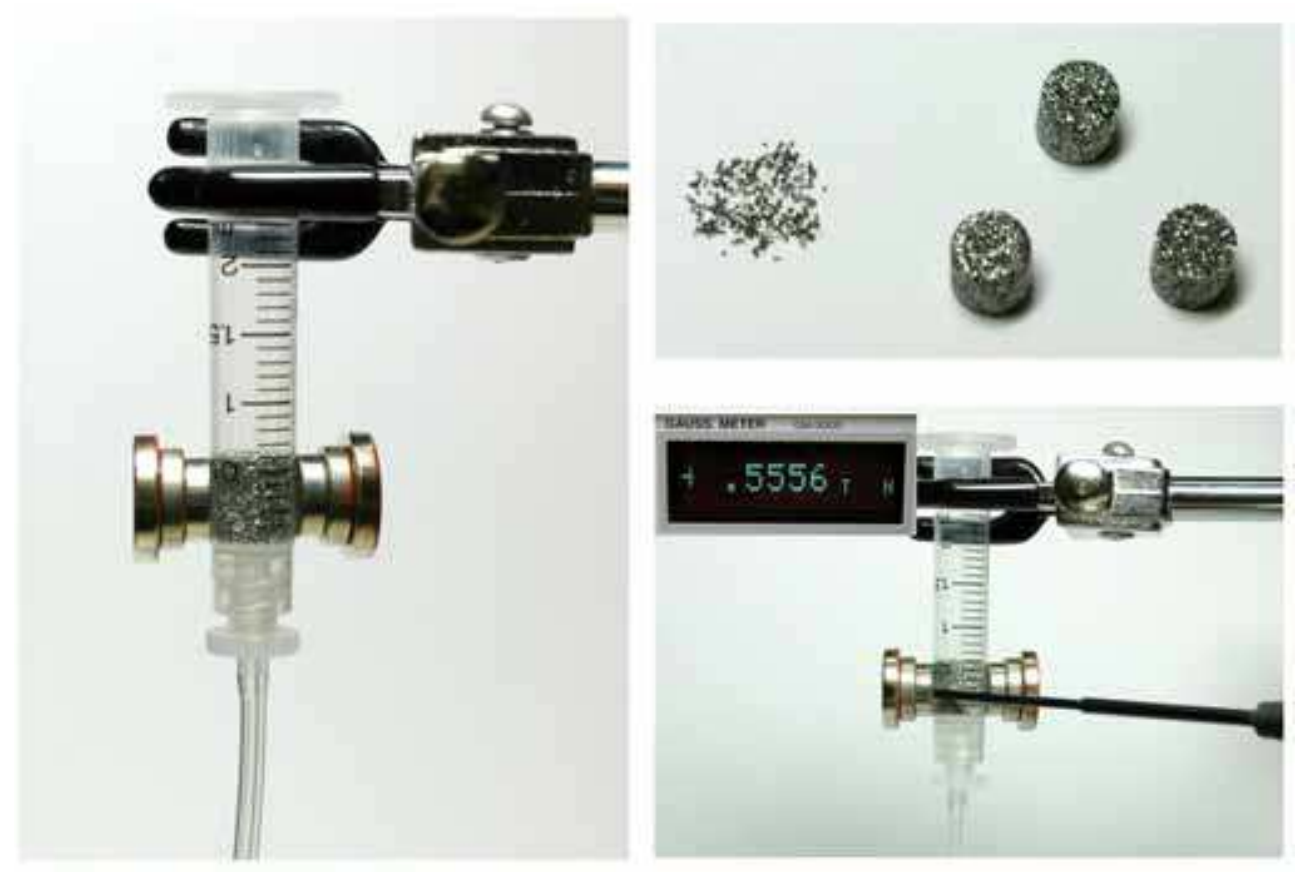

Fig. 8. Photograph of the stainless filter used for the purification of the cationic lipid-coated iron nitride/ metallic oxide nanocomposite. 

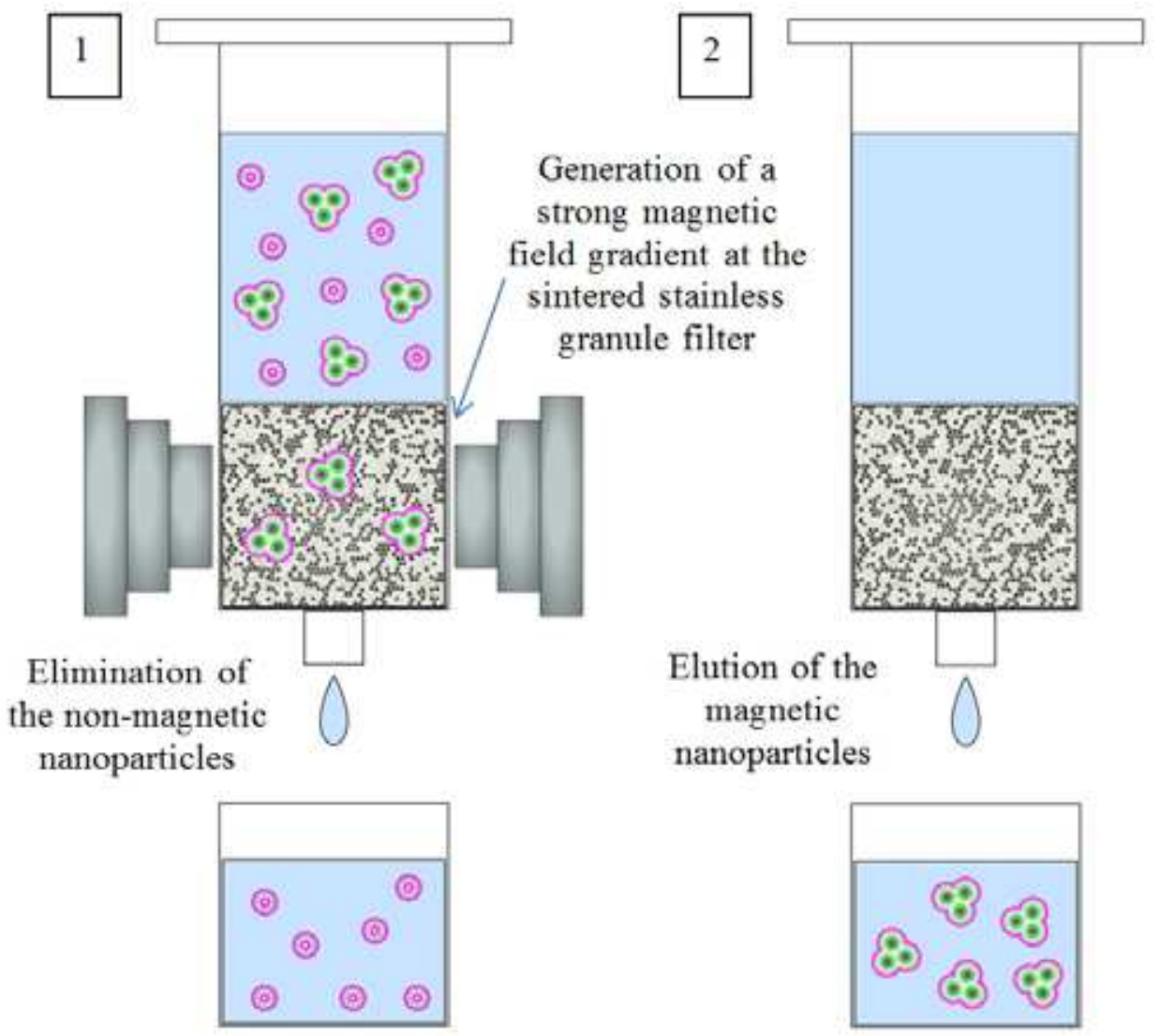

Generation of a strong magnetic field gradient at the sintered stainless granule filter
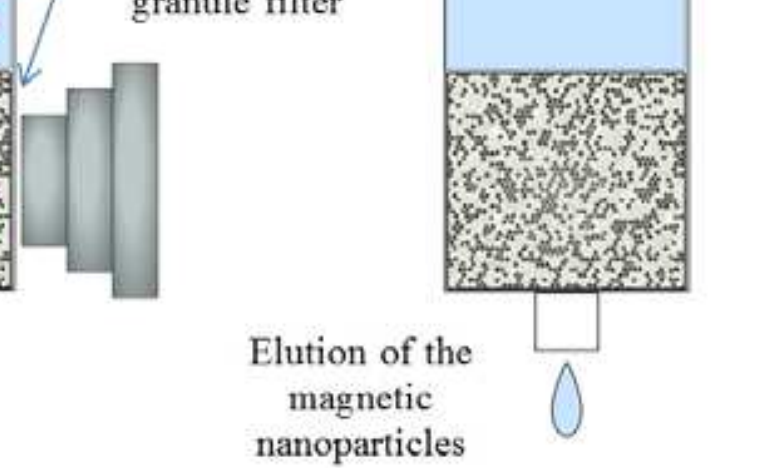

Fig. 9. Schematic representation of the stainless filter used for the purification of the cationic lipid-coated iron nitride/ metallic oxide nanocomposite. 

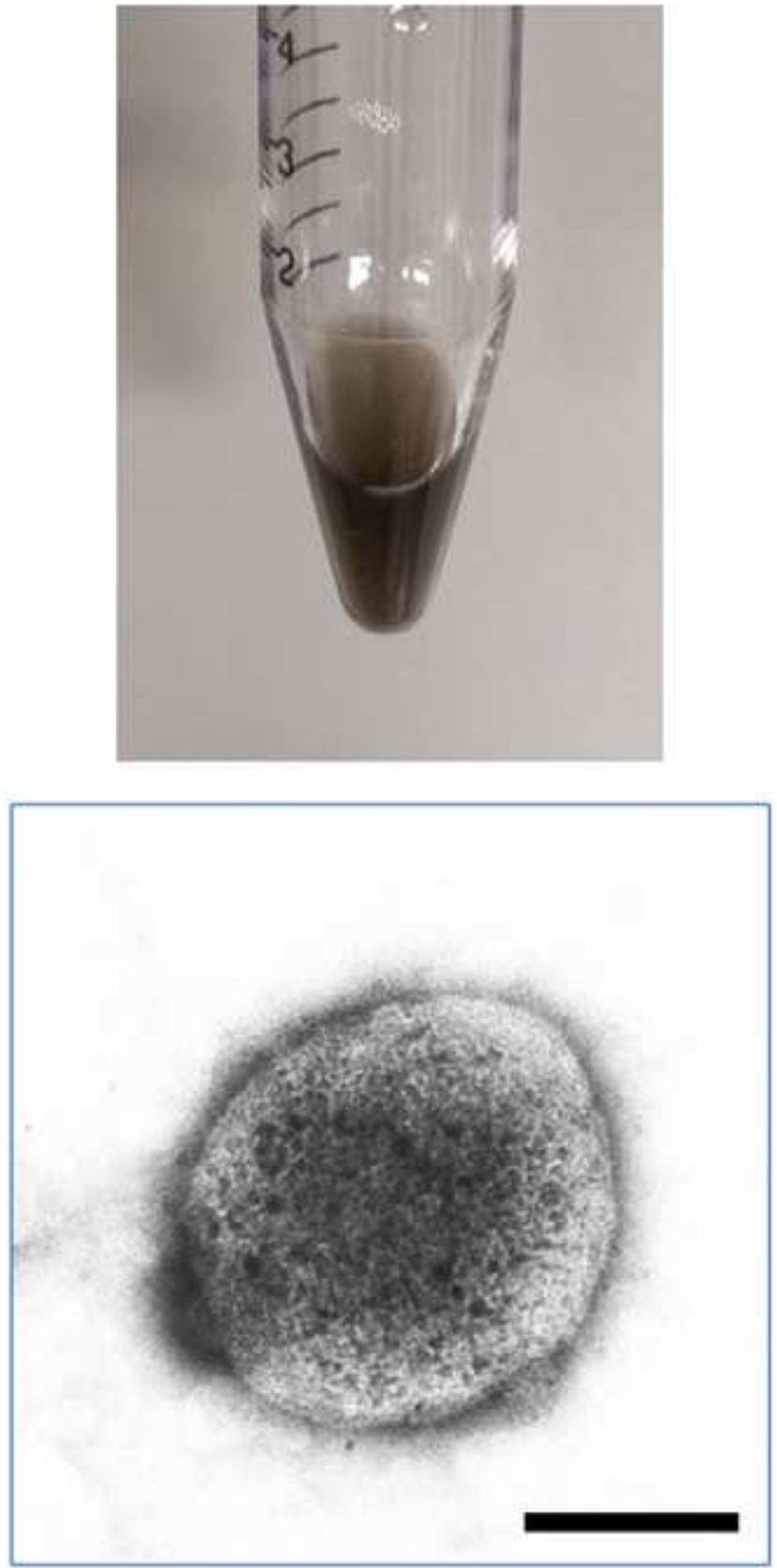

Fig. 10. Photograph and transmission electron micrograph (negative staining: Woodcock et al., 1991) of the cationic lipid-coated iron nitride/ metallic oxide, bar: $200 \mathrm{~nm}$. 


\section{Magnetic attraction of the iron nitride/metallic oxide/oleic acid/cationic lipid nanocomposite}

The speed of magnetic attraction of the FeN-based nanocomposite and iron oxide based nanoparticles was compared $(0-7.5 \mathrm{~min})$. One hundred microliters of the aqueous solution containing $100 \mu \mathrm{g}$ of each nanoparticle was placed in each of the wells of a 96 well microplate and a magnetic field $(200 \mathrm{mT})$ was irradiated under the well (Fig. 11). The magnetic attraction of these nanoparticles was recorded using a digital camera (Fig. 12). We confirmed that LipoFeN (iron nitride crystal-lipid nanostructures) were magnetically guided 1.5 to 2 times more quickly than PolyMagTM (iron oxide crystal-polymer nanostructures: OZ Biosciences, Marseille, France) (Fig. 13).
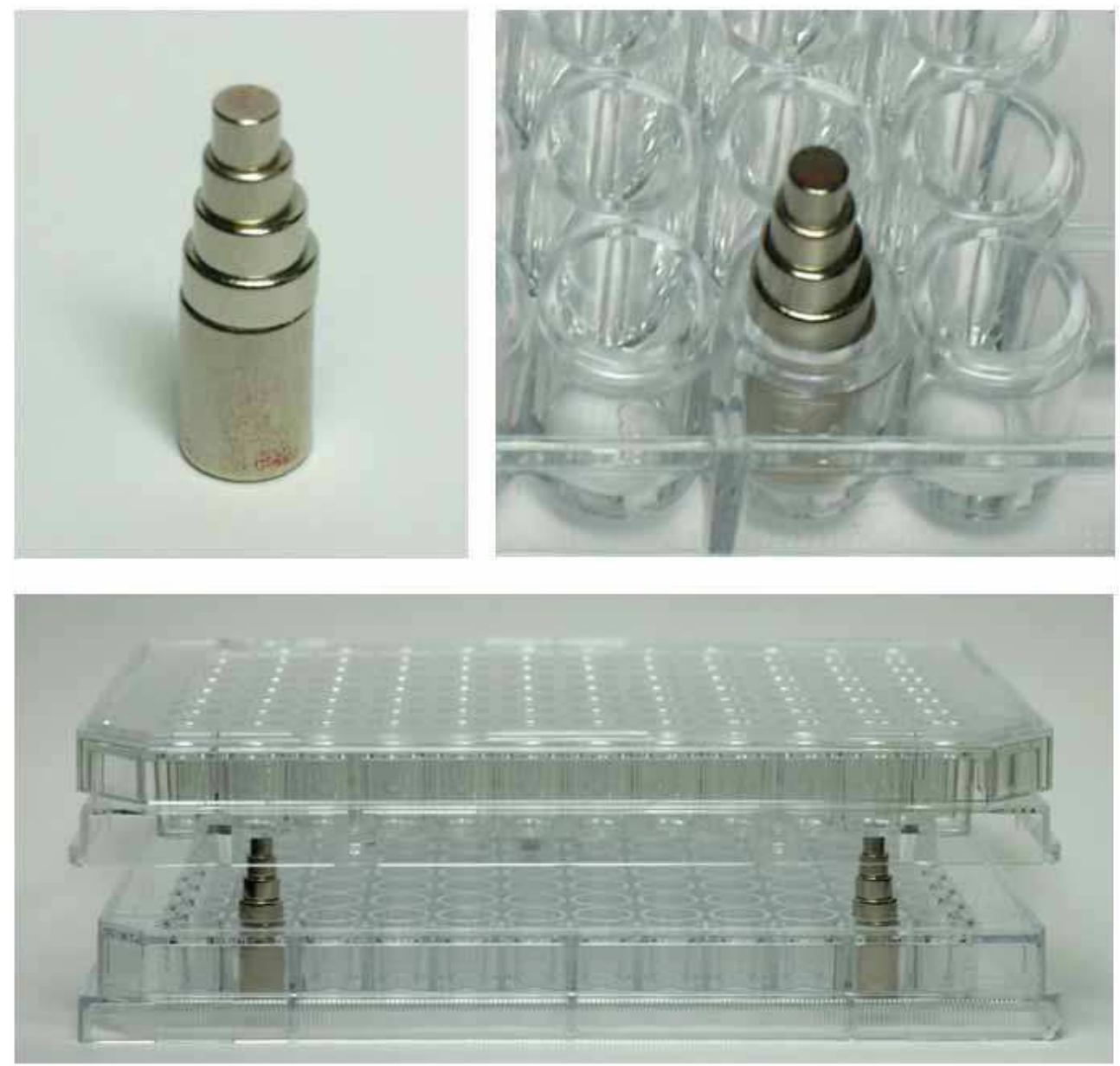

Fig. 11. The magnetic guidance of the magnetic nanoparticles using 96 well microplates. 

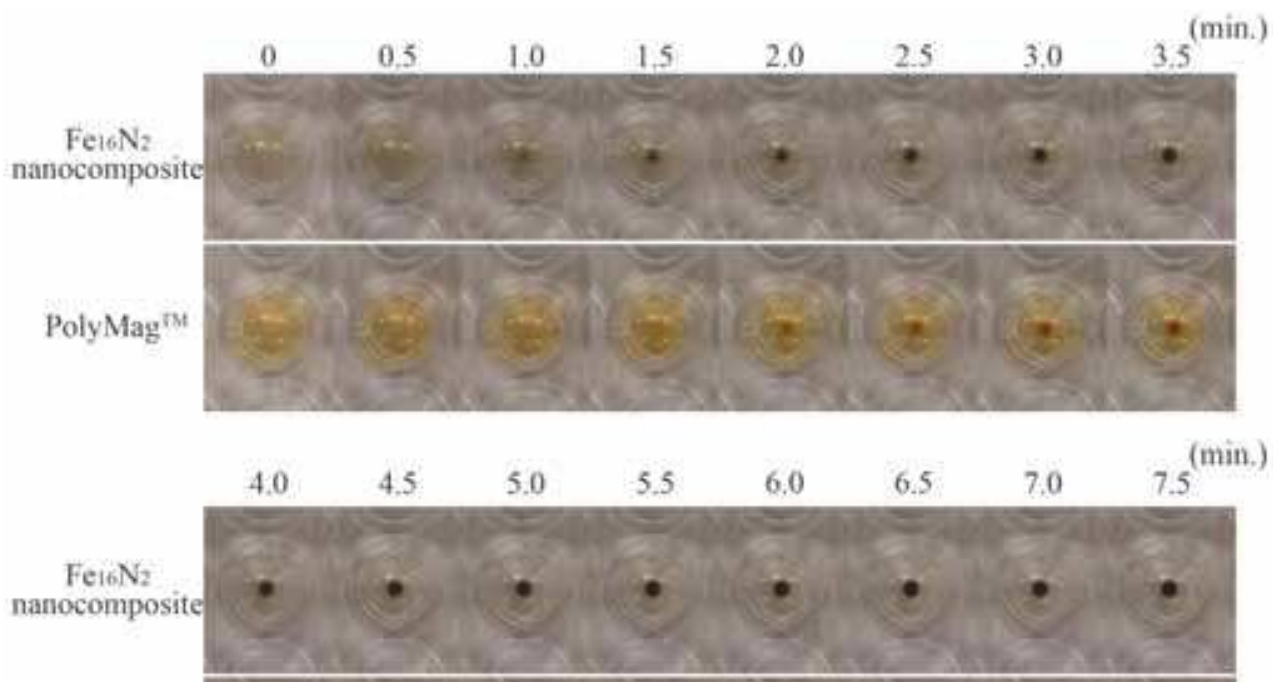

PolyMag ${ }^{\text {IS }}$

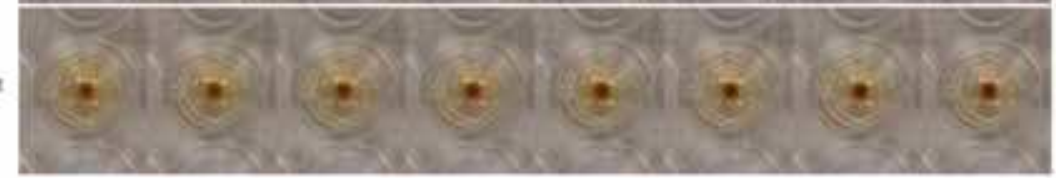

Fig. 12. The speed of the magnetic attraction of the cationic lipid-coated iron nitride/ metallic oxide nanocomposite compared with iron oxide-based nanoparticles.

\section{The gene silencing in cells induced by the magnetically guided siRNA delivered by the iron nitride/metallic oxide/oleic acid/cationic lipid nanocomposite}

Under a magnetic field, the gene silencing effect of of LipoFeN, LipoMag (iron oxide crystal-lipid nanostructures) and PolyMagTM loaded with the luciferase-targeting siRNA were compared in a luciferase-expressing cancer cell line (Fig. 14). A human colon cancer cell line stably expressing luciferase (HT-29-luc2: Caliper, Alameda, CA) was cultured in McCoy's 5A (Invitrogen, Carlsbad, CA) complete medium containing $10 \%$ heatinactivated fetal bovine serum (Sigma). Cells were incubated at $37{ }^{\circ} \mathrm{C}$ in a humidified atmosphere of $5 \% \mathrm{CO}_{2}$.

Cells ( 1 x 104/ well) were cultured in 96 well plates for $12 \mathrm{hr}$. Either $25 \mu \mathrm{l}$ of siRNALuc (Table 4) or $25 \mu \mathrm{l}$ of siRNANC was mixed with $25 \mu \mathrm{l}$ of each type of magnetic nanoparticles for 10 min at room temperature. Cell culture medium was removed from the 96 well plate and cells were washed twice with PBS. Cells were incubated with the obtained $50 \mu \mathrm{l}$ of siRNAmagnetic nanoparticle complex at $37^{\circ} \mathrm{C}$ using a magnetic plate (Fig. 15). At 5 min after the initiation of the incubation, these complexes were removed, cells were washed twice with PBS and culture medium was dispensed to each well. Finally, luciferase activity was quantified at $48 \mathrm{hr}$ after the incubation with these complexes. Luciferase activity was quantified as described previously (Takahashi et al., 1997). Briefly, cells were homogenized 

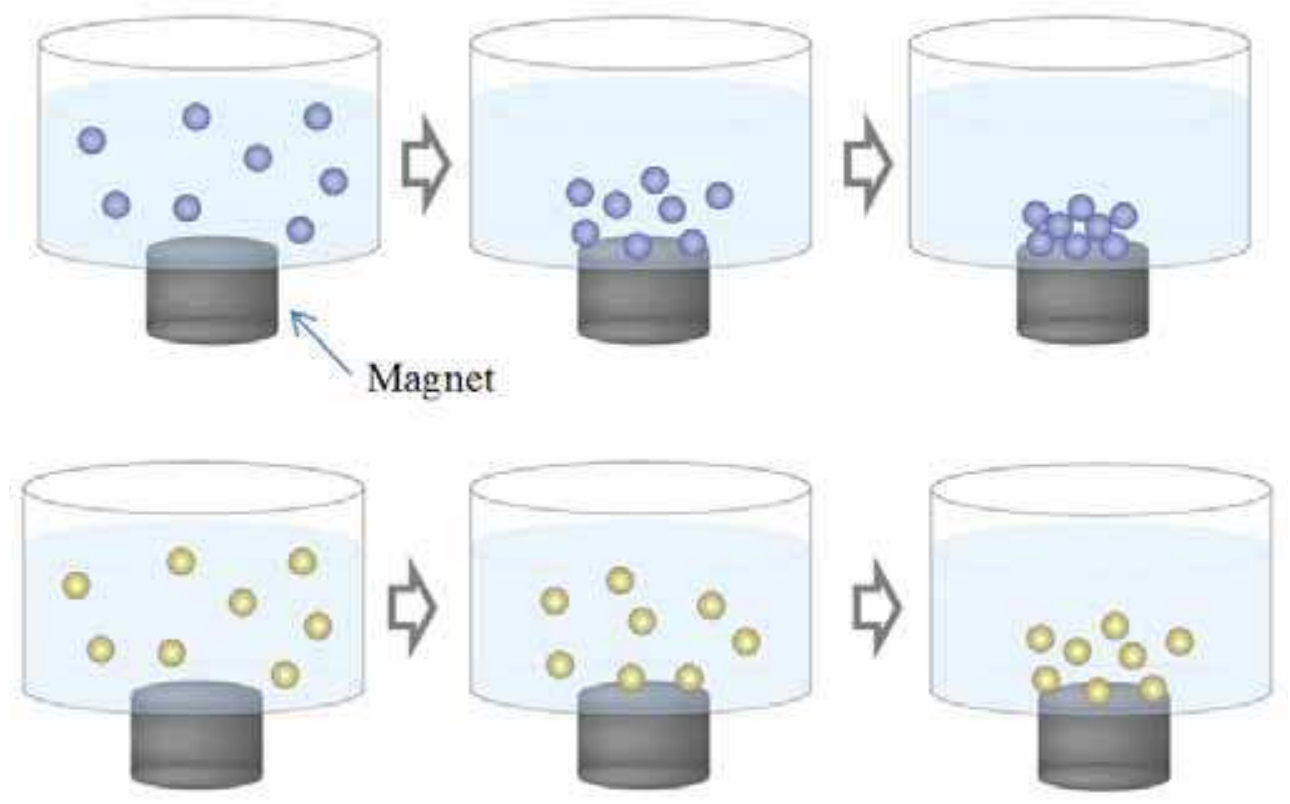

Fig. 13. Schematic representation of the magnetic attraction of the iron nitride-based LipoFeN (blue) compared with the iron oxide-based PolyMag (brown).

in cell lysis reagent (Toyo ink, Tokyo, Japan), and incubated for $15 \mathrm{~min}$ at room temperature. After centrifugation, $2.5 \mu \mathrm{l}$ of the supernatant were mixed with $100 \mu \mathrm{l}$ of luciferase assay reagent (Toyo ink), and the emission of light was measured with a luminometer (lumat LB9501; Berthold Designs, Berlin, Germany). For analysis of the total protein content, $10 \mu \mathrm{l}$ of supernatant was assayed using the bicinchonic acid method, as described previously (Namiki et al., 1998).

\begin{tabular}{|l|}
\hline Sense sequence: 5'-CGUACGCGGAAUACUUCGAdTdT-3' \\
Antisense sequence: 5' - UCGAAGUAUUCCGCGUACGdTdT-3' \\
Target DNA sequence: AACGTACGCGGAATACTTCGA
\end{tabular}

Table 4. The sequence of siRNA targeted to the luciferase gene and the target sequence of luciferase DNA (Elbashir et al., 2001). All Stars NC siRNA (siRNANC: Qiagen, Valencia, CA), which was used as the negative control nonsense siRNA, was designed to be a non-targeting sequence bearing no significant homology to the sequence of the human or murine transcripts. The negative control was used to eliminate non-specific off-target effects. These siRNAs were the most thoroughly tested and validated as a positive control or a negative control available from Qiagen. 

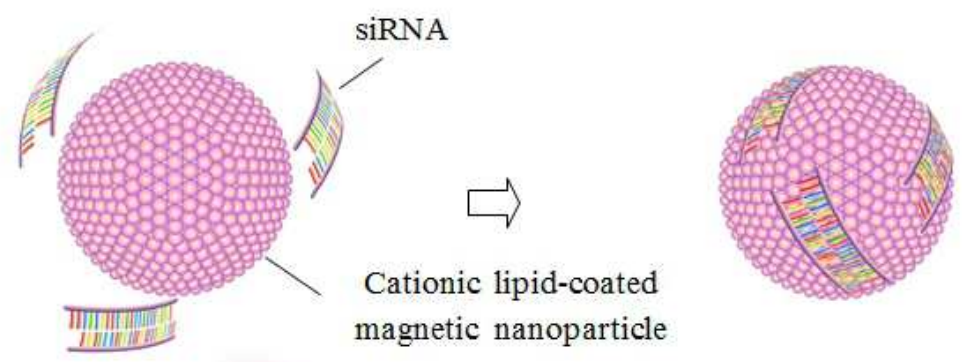

magnetic nanoparticle

Magnetic guidance

of nanoparticles to

luciferase-expressing

cancer cells
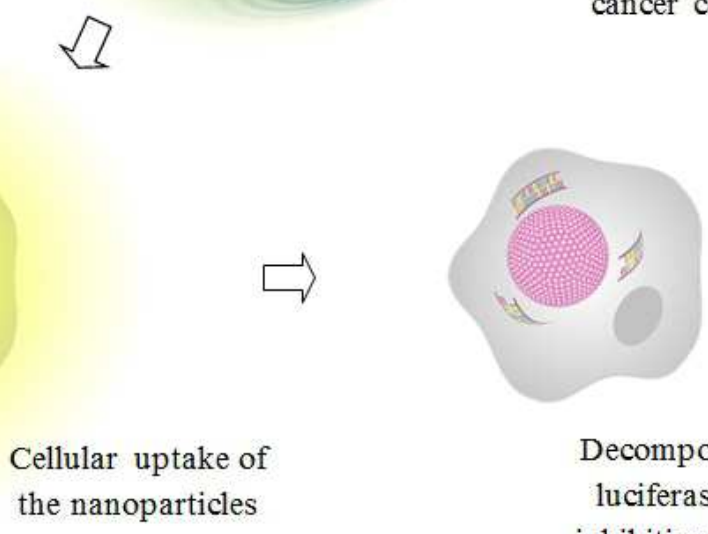

Decomposition of the

luciferase gene and

inhibition of luciferase

expression

Fig. 14. Schematic representation of the magnetic guidance of siRNA loaded with the magnetic nanoparticles and of the silencing of the luciferase gene.

The gene silencing effect (the \% knockdown of luciferase activity) of each type of magnetic nanoparticle was calculated (Fig. 16) using the following formula.

[the \% knockdown of luciferase activity]= $100-100 \mathrm{x}$ [the activity of luciferase for samples transfected with siRNAluc] / [the activity of luciferase for samples transfected with siRNANC]. 

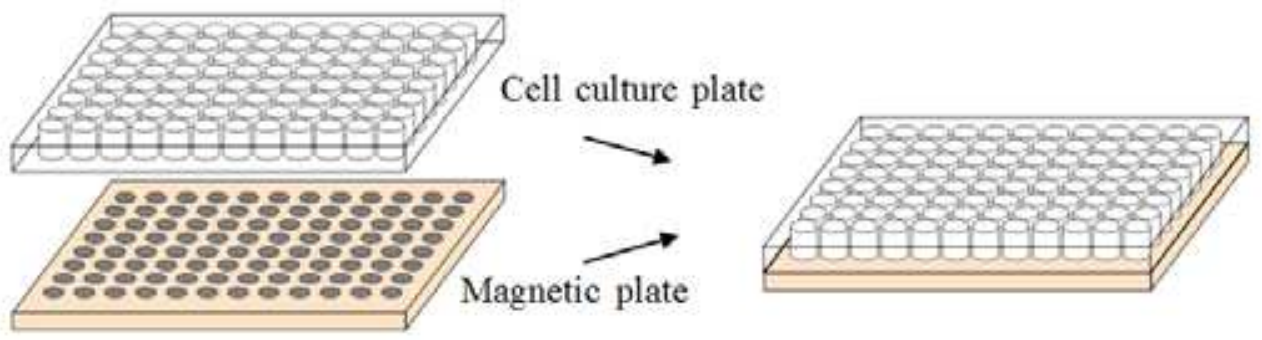

Fig. 15. Schematic representation of the magnetic attraction of the magnetic nanoparticles to the cultured cells using a magnetic plate $(200 \mathrm{mT})$.

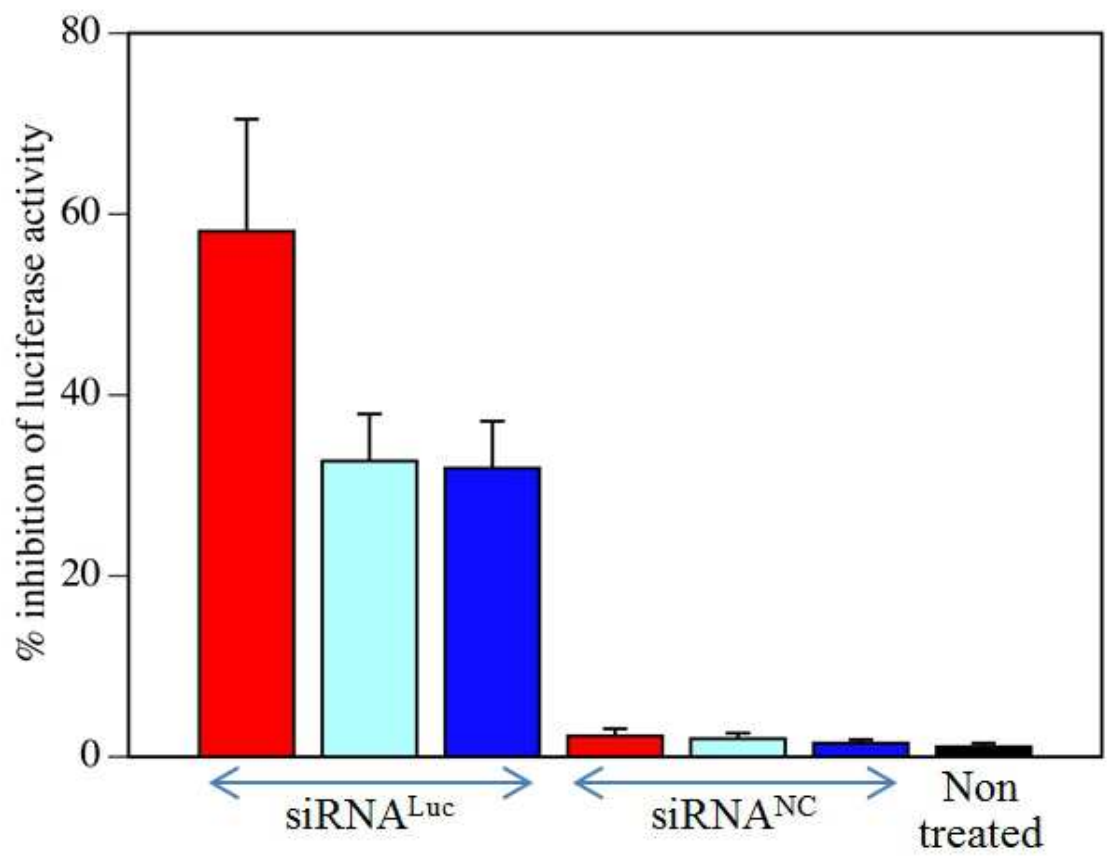

Fig. 16. The magnetically guided target gene silencing of the $\mathrm{Fe}_{16} \mathrm{~N}_{2} /$ cationic lipid (red), iron oxide/ cationic lipid (light blue) and iron oxide-based PolyMagTM (blue) in cancer cells. Cells were incubated with LipoFeN/ siRNALuc, LipoFeN/ siRNANC, LipoMag/ siRNALuc, LipoMag/ siRNANC, (all of which included 90-720 ng of total lipids and 7.8-31.3 ng of siRNA), PolyMagTM/ siRNALuc or PolyMagTM/ siRNANC (both of which included 12.5-100 nl of PolyMagTM and 7.8-31.3 ng of siRNA). At $48 \mathrm{~h}$ after the incubation with the complexes for $5 \mathrm{~min}$, the degree of the knockdown of luciferase-expression was evaluated. LipoFeN containing $360 \mathrm{ng}$ of total lipid and $15.6 \mathrm{ng}$ of siRNA ${ }^{\mathrm{Luc}}$ per $1 \times 10^{4}$ cells displayed a greater gene silencing effect than LipoMag (containing $360 \mathrm{ng}$ of total lipid) and PolyMagTM under each optimized condition. The data given are the averages of two different experiments, each performed in triplicate $(n=6)$; bars, SD. 


\section{Cytotoxicity of the iron nitride/metallic oxide/oleic acid/cationic lipid nanocomposite}

We evaluated the cytotoxicity of magnetic nanoparticles by the $\mathrm{LDH}$ (lactate dehydrogenase) release assay. This assay is recommended instead of the MTT assay (Heeg et al., 1985) when the magnetic lipid nanoparticle-mediated cytotoxicity is measured (Soenen et al., 2007). In particular, the LDH release assay (Korzeniewski et al., 1983; Decker et al., 1988) is used for the quantitative analysis of cell death be measuring the LDH activity liberated from cells with cell membrane injuries, such the cell membrane lysed by drugs. This assay can be used for the determination of the toxicity of various agents, utilizing cultured cells. In the presence of NAD, $\mathrm{LDH}$ catalyzes the conversion of lactate to pyruvate. Lactate is oxidized to pyruvate and an equivalent amount of NAD is reduced to NADH. The $\mathrm{NADH}$ formed reduces nitrotetrazolium blue in the presence of diaphorase to produce blue colored Diformazan (Fig. 17), the absorbance wavelength of which is $560 \mathrm{~nm}$.

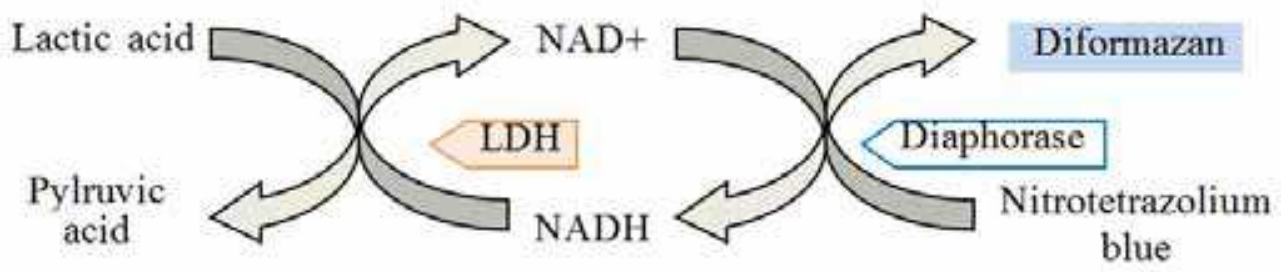

Fig. 17. Principle of the $\mathrm{LDH}$ release assay

HT-29-luc2 cells ( $1 \times 10^{4}$ cells/ well of a 96 well microplate) were incubated with each type of magnetic nanoparticles or with culture medium alone for 5 min under the magnetic field. After the removal of each medium, cells were washed twice with PBS and cultured with culture medium for $48 \mathrm{hr}$ in a $5 \% \mathrm{CO}_{2}$ incubator at $37{ }^{\circ} \mathrm{C}$. After the removal of the culture medium, cells were washed twice with PBS and $75 \mu \mathrm{l}$ of $0.2 \%$ Tween 20 / PBS was added to the well. The plate was allowed to stand for $15 \mathrm{~min}$ at room temperature and moderately agitated. The plates were centrifuged for $3 \mathrm{~min}$ at $1000 \mathrm{rpm}$ and $50 \mu \mathrm{l}$ of supernatant was collected. Five milliliters of color reagent containing nitrotetrazolium blue $(3.7 \mathrm{mg})$, diaphorase and $\mathrm{NADH}$, and $5 \mathrm{ml}$ of buffer solution containing DL-lithium lactate $(25 \mathrm{mg})$ were mixed to obtain the coloring solution. Fifty microliters of this coloring solution and 50 $\mu \mathrm{l}$ of supernatant were mixed. At $45 \mathrm{~min}$ after the mixture (room temperature), $100 \mu \mathrm{l}$ of hydrochloric acid $(0.5 \mathrm{~mol} / \mathrm{l})$ were added to each well. Finally, the absorbance of the reaction mixture was measured with a microplate reader at $560 \mathrm{~nm}$ after termination of the coloring reaction. The percentage of cell viability was calculated (Fig. 18) using the following formula.

$$
\% \text { cell viability }=\mathrm{S} / \mathrm{N} \times 100
$$

(S: Absorbance of the sample; $\mathrm{N}$ : Absorbance of non-treated negative control cells) 


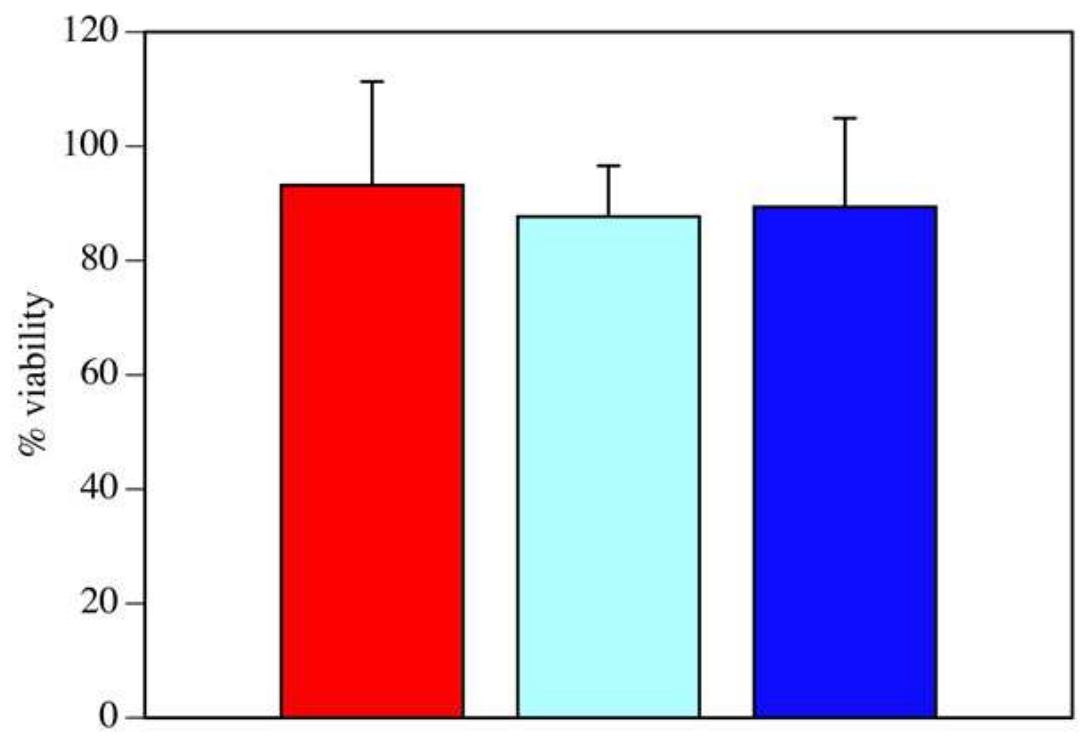

Fig. 18. The cytotoxicity of the iron nitride-based nanocomposite compared with the iron oxide-based nanocomposite. To eliminate non-specific cytopathic effects, we confirmed that cell viability was over $85 \%$ of the non-treated cell at $48 \mathrm{~h}$ after gene silencing under the optimized conditions of siRNA-transfection using an $\mathrm{LDH}$ release assay procedure. Cells were incubated with LipoFeN/ siRNALuc (red), LipoMag/ siRNALuc (light blue) or PolyMagTM/ siRNALuc (blue) in a similar manner as Figure 16. The data given are the averages of two different experiments, each performed in triplicate $(n=6)$; bars, SD.

\section{Conclusion}

We were able to successfully enhance the gene silencing effect using a ferromagnetic iron nitride-based nanocomposite instead of an iron oxide-based nanocomposite. In summary, the newly devised ferromagnetic crystal-lipid nanostructures comprise a highly efficient, magnet-guided delivery system of siRNA. Using the $\mathrm{Fe}_{16} \mathrm{~N}_{2}$ / cationic lipid nanocomposite achieved a better gene silencing effect than the major commercially available iron oxidebased magnetic vector, PolyMagTM, even with a short incubation time, and the expression of the target gene was effectively inhibited. The formulations of iron nitride crystal-lipid nanostructures clearly have the potential for widespread use as high-performance gene delivery systems for cancer cell-targeted RNA interference.

\section{Acknowledgments}

We dedicate this work to the late T. Terada and the late K. Nariai. We would like to acknowledge Yukiko Ishii, Yoko Yumoto and Shuichi Nakagawa for their assistance. This work was supported by a Funding Program for Next Generation World-Leading Researchers (LS114), from JSPS and by an Industrial Technology Research Grant, Program (08C46049a), from the NEDO of Japan. Pacific Edit reviewed the manuscript prior to submission. 


\section{References}

Fire, A. et al. Potent and specific genetic interference by double-stranded RNA in Caenorhabditis elegans. Nature 391, 806-811 (1998).

Li, C.X. et al. Delivery of RNA interference. Cell Cycle 5, 2103-2109 (2006).

Toub, N. et al. Innovative nanotechnologies for the delivery of oligonucleotides and siRNA. Biomed. Pharmacother. 60, 607-620 (2006).

Namiki, Y. et al. A novel magnetic crystal-lipid nanostructure for magnetically guided in vivo gene delivery. Nat. Nanotechnol. 4, 598-606 (2009).

Xie, J. et al. Iron oxide nanoparticle platform for biomedical applications. Curr. Med. Chem. 16, 1278-1294 (2009).

Lin, M.M. et al. Development of superparamagnetic iron oxide nanoparticles (SPIONS) for translation to clinical applications. IEEE Trans. Nanobioscience 7, 298-305 (2008).

Laurent, S. et al. Magnetic iron oxide nanoparticles: synthesis, stabilization, vectorization, physicochemical characterizations, and biological applications. Chem. Rev. 108, 2064-2110 (2008).

Gupta, A.K. et al. Synthesis and surface engineering of iron oxide nanoparticles for biomedical applications. Biomaterials 26, 3995-4021 (2005).

Sugita, Y. et al. Magnetic and Mössbauer studies of single-crystal $\mathrm{Fe}_{16} \mathrm{~N}_{2}$ and $\mathrm{Fe}-\mathrm{N}$ martensite films epitaxially grown by molecular beam epitaxy. J. Appl. Phys. 76, 6637-6641 (1994).

Takahashi, H. et al. Perpendicular uniaxial magnetic anisotropy of $\mathrm{Fe}_{16} \mathrm{~N}_{2}$ (001) single crystal films grown by molecular beam epitaxy. IEEE Trans. Magn. 35, 2982-2984 (1999).

Hattori, T. et al. Magnetic particles of $\mathrm{Fe}_{16} \mathrm{~N}_{2}$ fine particles. J. Magn. Soc. Jpn. 25, 927-930 (2001).

Sun, S. et al. Monodisperse FePt nanoparticles and ferromagnetic FePt nanocrystal superlattices. Science 287, 1989-1992 (2000).

Sasaki, Y. et al. Development of NanoCAP Technology for High-Density Recording. IEEE Trans. Magn. 41, 3241-3243 (2005).

Woodcock, C.L. et al. Ultrastructure of chromatin: negative staining of isolated fibers. J. Cell Sci. 99, 99-106 (1991).

Takahashi, T. et al. Induction of the suicide HSVtk gene by activation of the Egr-1 promoter with radioisotopes. Hum. Gene Ther. 8, 827-833 (1997).

Namiki, Y. et al. Gene transduction for disseminated intraperitoneal tumor using cationic liposomes containing non-histone chromatin proteins. Gene Ther. 5, 240-246 (1998).

Elbashir, S.M. et al. Duplexes of 21-nucleotide RNAs mediate RNA interference in cultured mammalian cells. Nature 411, 494-498 (2001).

Korzeniewski, C. et al. An enzyme-release assay for natural cytotoxicity. J. Immunol. Methods 64, 313-320 (1983).

Decker, T. et al. A quick and simple method for the quantitation of lactate dehydrogenase release in measurements of cellar cytotoxicity and tumor necrosis factor activity. J. Immunol. Methods 115, 61-69 (1988). 
Heeg, K. et al. A rapid colorimetric assay for the determination of IL-2-producing helper T cell frequencies. JImmunol. Methods 77, 237-246 (1985).

Soenen, S.J. et al. Optimal conditions for labeling of 3T3 fibroblasts with magnetoliposomes without affecting cellular viability. Chembiochem. 8, 2067-2077 (2007). 


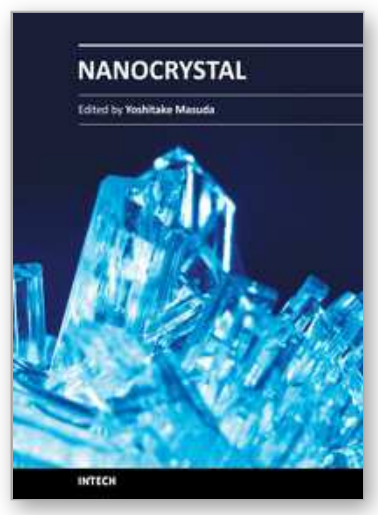

\author{
Nanocrystal \\ Edited by Dr. Yoshitake Masuda
}

ISBN 978-953-307-199-2

Hard cover, 494 pages

Publisher InTech

Published online 28, June, 2011

Published in print edition June, 2011

We focused on cutting-edge science and technology of Nanocrystals in this book. â€œNanocrystalâ€ is expected to lead to the creation of new materials with revolutionary properties and functions. It will open up fresh possibilities for the solution to the environmental problems and energy problems. We wish that this book contributes to bequeath a beautiful environment and valuable resources to subsequent generations.

\title{
How to reference
}

In order to correctly reference this scholarly work, feel free to copy and paste the following:

Yoshihisa Namiki, Satoshi Matsunuma, Tetsutaro Inoue, Shigeo Koido, Akihito Tsubota, Yoji Kuse and Norio Tada (2011). Magnetic Nanostructures for Biomedical Applications: An Iron Nitride Crystal/Cationic Lipid Nanocomposite for Enhanced Magnetically Guided RNA Interference in Cancer Cells, Nanocrystal, Dr. Yoshitake Masuda (Ed.), ISBN: 978-953-307-199-2, InTech, Available from: http://www.intechopen.com/books/nanocrystal/magnetic-nanostructures-for-biomedical-applications-an-ironnitride-crystal-cationic-lipid-nanocompo

\section{INTECH}

open science | open minds

\section{InTech Europe}

University Campus STeP Ri

Slavka Krautzeka 83/A

51000 Rijeka, Croatia

Phone: +385 (51) 770447

Fax: +385 (51) 686166

www.intechopen.com

\section{InTech China}

Unit 405, Office Block, Hotel Equatorial Shanghai

No.65, Yan An Road (West), Shanghai, 200040, China

中国上海市延安西路65号上海国际贵都大饭店办公楼405单元

Phone: +86-21-62489820

Fax: +86-21-62489821 
(C) 2011 The Author(s). Licensee IntechOpen. This chapter is distributed under the terms of the Creative Commons Attribution-NonCommercialShareAlike-3.0 License, which permits use, distribution and reproduction for non-commercial purposes, provided the original is properly cited and derivative works building on this content are distributed under the same license. 